\title{
Edge Oleylaminated Graphene as Ultra-Stable Lubricant Additive for Friction and Wear Reduction
}

Shuang Zhao, Mingming Niu, Peng Peng, Yuanhui Cheng and Yun Zhao*

Graphene has caught growing interest in the field of lubricant additives for its lubricating and antifraying effect. However, the critical agglomeration and sedimentation of graphene particles strongly impede its industrial applications. Here, we proposed a facile way to massively prepare edge-oleylaminated graphene (EOG) via ball milling method. The EOG was well dispersed in lubricant and showed longer than 8 months stability for its extremely thin structures and strong affinity with lubricant. The viscosity index (VI) of base lubricant was greatly improved from 81 to 119 by adding an optimized EOG amount of $0.1 \mathrm{wt} . \%$. Besides, the wear scar diameter (WSD) decreased from 0.88 to $0.46 \mathrm{~mm}$, while the maximum nonseizure load $\left(\mathrm{P}_{\mathrm{B}}\right)$ and the sintering load $\left(\mathrm{P}_{\mathrm{D}}\right)$ increased $64.86 \%$ and $56.18 \%$, respectively. The enhanced VI indicates EOG additive could upgrade the base oil from normal grade to special grade. The obvious improvement of wear resistance and load-carrying capacity demonstrates EOG is an ultrastable and effective additive for specific lubricants.

Keywords: Edge-oleylaminated graphene; Ball milling; Lubricant additive; Long-term stability; Friction reduction

Received 18 June 2019, Accepted 20 August 2019

DOI: $10.30919 / \mathrm{es} 8 \mathrm{~d} 807$

\section{Introduction}

Mechanical friction has caused huge energy loss in various mechanical operations. For example, about $33 \%$ of the vehicle' $\mathrm{s}$ energy is used to overcome the mechanical friction. ${ }^{1-4}$ Nowadays using lubricants to reduce the friction and wear has become the most effective ways to save frictional energy loss. The lubricant is generally composed of base oil and variety of additives. The additives are generally used to improve its properties in antifraying, lubricating, antioxidation, etc. ${ }^{5}$ In recent years, the ever-rising industrial and environmental demands for high tribological performance and long-life lubricants have been drivers for the developing of superior lubricant additives.

Recently, two dimensional (2D) nanomaterials, such as graphene, molybdenum disulfide, boron nitride, etc., have attracted growing interest as lubricant additives due to their high mechanical strength and atomic lubricating properties. ${ }^{6-8}$ The 2D graphene has become the most promising candidate among these materials for its superior mechanical robustness, low sliding-forces between graphene layers, high electrical and thermal conductivities. ${ }^{9-13}$ However, the stacking effect originated from the interlayer $\pi-\pi$ interaction of graphene results in serious sedimentation and agglomeration problems in long-term dispersion. ${ }^{14-16}$ To overcome this low dispersing stability, covalent organic modifications have been developed as an effective way to design high dispersible and long-term stable graphene additives. ${ }^{5,17-19} \mathrm{~S}$. Stankovich et al. ${ }^{20}$ prepared a series of functionalized graphene by grafting carboxyl groups, hydroxyl groups and isocyanates to graphene structure. The modified graphene can be uniformly dispersed into a variety of polar aprotic solvents for weeks. Lin et al. ${ }^{21}$ reported that the stearic and oleic acids modified graphene platelets significantly improved the wear resistance and load carrying capacity of lubricating oil. S. Bagheri et al. ${ }^{22}$ introduced a triazole modified graphene via click chemistry as anti-wear additive for lubricating oil, which showed lower friction coefficient and better wear performance compared to the base oil. Besides the modified graphene can be homogeneously dispersed in the base oil for 30 days without sedimentation. The reported works indicate that the organic modified 
graphene is stable and effective additive to improve the lubricating and thermal properties of lubricates. However, the additive in these works are always kept at low concentration for the serious sedimentation and aggregation problems. The high graphene concentration is considered to be good to improve the tribological properties of base oil. Therefore it still remains big challenge to uniformly disperse the high concentrated graphene in lubricating oil with long-term stability.

In this paper, we used ball milling method to exfoliate the graphite powder into edge-carboxylated graphene (ECG) under carbon dioxide atmosphere. ${ }^{23-26}$ The ball milling method has characteristics such as simple preparation process, energy saving and environmental benign for massively production. ${ }^{27}$ The ECG was further grafted with the oleophilic oleylamine molecule to prepare edge-oleyaminated graphene (EOG). Oleylamine is selected as functional group for its thermal stability and miscibility with various oils. ${ }^{28}$ The dispersibility and stability of EOG in lubricants was measured to study the effect of oleylamination. The tribological properties of lubricants were further studied to evaluate the EOG additive. The facile preparation method is considered as a new strategy to design graphene additives with long-term stability and superior tribological properties.

\section{Experimental Section}

\subsection{Materials}

Graphite powder (300 mesh, 99.95 wt.\%), oleylamine (80 90 wt.\%), anhydrous ethanol ( $\geqslant 99.5$ wt.\%), hydrochloric acid ( $\mathrm{HCl}, 36 \sim 38$ wt.\% ) and 4-dimethylaminopyridine (DMAP, AR) were purchased from Beijing Warwick Ruike Chemical Co., Ltd. Base oil $(150 \mathrm{~N})$ was a commercial available product obtained from Liuzhou Advanced Lubricant Co., Ltd. Carbon dioxide gas $\left(\mathrm{CO}_{2}\right)$ was supplied by Shiyuan Precision (Beijing) Aerodynamics Technology Development Co., Ltd. All chemicals were used as received without further purification.

\subsection{Synthesis of ECG}

ECG was prepared from graphite powder via ball-milling process as illustrated in Scheme 1. The ball milling was conducted in a planetary ball-mill machine under carbon dioxide atmosphere. In a typical experiment, $5 \mathrm{~g}$ graphite powders were placed into a stainless steel capsule containing zirconia balls of $5 \mathrm{~mm}$ in diameter. After that, the reactor was sealed and pressurized with carbon dioxide at 1.5 MPa. The capsule was then fixed in the planetary ballmill machine and agitated with $500 \mathrm{rpm}$ for $48 \mathrm{~h}$. The resultant product was Soxhlet extracted with $1 \mathrm{M}$ aqueous $\mathrm{HCl}$ solution to completely acidify carboxylates and to remove the metallic impurities. The final dark black products was collected after consecutively filtration and vacuum drying at $70{ }^{\circ} \mathrm{C}$.

\subsection{Synthesis of EOG}

The EOG was obtained by grafting oleylamine to ECG in a stirring tank (Scheme 1). Generally, $1 \mathrm{~g}$ ECG, $10 \mathrm{~mL}$ oleylamine and $50 \mathrm{mg}$ of DMAP were thoroughly mixed and reacted at $120{ }^{\circ} \mathrm{C}$ for $24 \mathrm{~h}$. After cooling down to room temperature, the product was thoroughly washed with anhydrous ethanol to remove the excess oleylamine. The products were then dried at $80{ }^{\circ} \mathrm{C}$ for $24 \mathrm{~h}$ before use.

\subsection{Characterization}

${ }^{13} \mathrm{C}-\mathrm{NMR}$ (Bruker AV300) was used to analyze the skeleton structure of EOG. The chemistry change of ECG and EOG was recorded by Fourier transform infrared (FTIR, Nicolet 8700) spectroscopywith $\mathrm{KBr}$ pellets at room temperature. Elemental analysis (EA) was conducted with Thermo Scientific Flash 2000. Raman spectra was carried out on LabRAM Aramis with $\mathrm{He}-\mathrm{Ne}$ as the excitation light source $(532 \mathrm{~nm})$. The crystalline structure of ECG and EOG were characterized by X-ray diffraction (XRD, D/MAX 2000X) with $\mathrm{Cu}-\mathrm{K} \alpha$ radiation $(\lambda=1.5424 \AA)$. Thermogravimetric analysis (TGA, TGA/DSC1/1100SF) was performed at

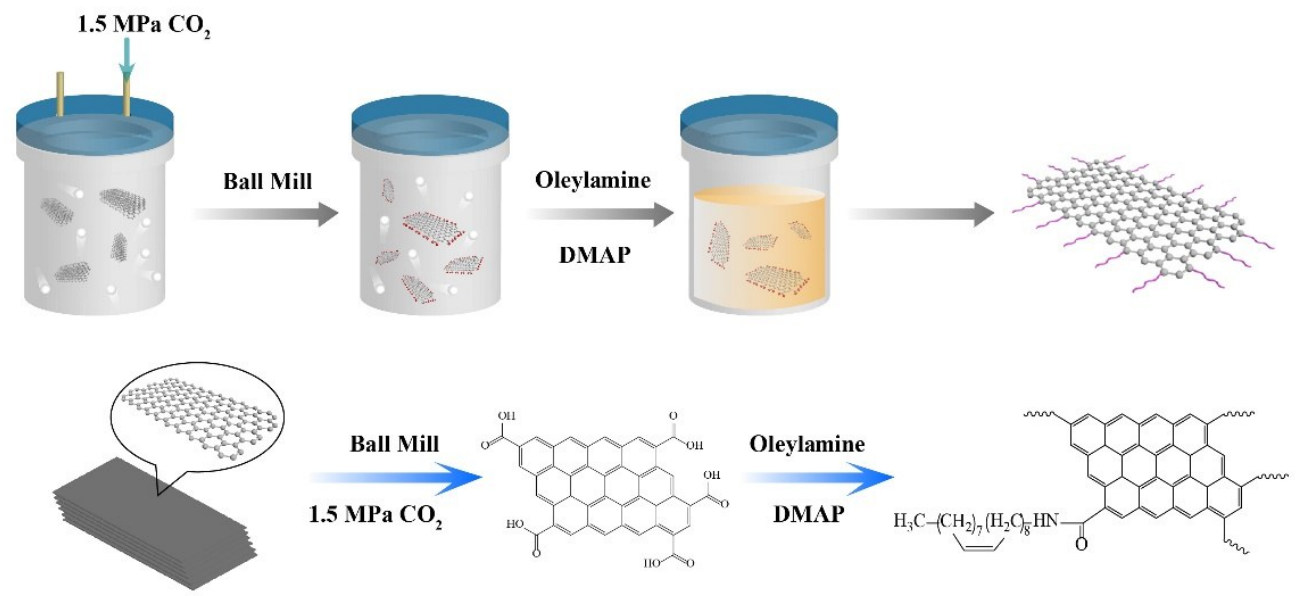

Scheme 1 The synthesis procedure of ECG and EOG. 
nitrogen atmosphere to evaluate the thermal stability of ECG and EOG. The transmission electron microscope (TEM) were performed on H-800 (Hitachi). Atomic Force Microscope (AFM, Dimension Icon) was used to measure the thickness of EOG. The oleophilicity of EOG was measured by contact angle tester (OCA 50AF, Germany) by using petroleum ether and mineral oil.

\subsection{Dispersity and Viscosity Index (VI) Measurement}

We prepared various samples for lubricating study by dispersing different amount of ECG or EOG into the base oil (150N). Generally, sample a: 0.2 wt.\% ECG; sample b: 0.05 wt.\% EOG; sample c: 0.1 wt.\% EOG; sample d: 0.2 wt.\% EOG; sample e: 0.5 wt.\% EOG; sample f: 1 wt.\% EOG.

The dispersibility of different amount ECG or EOG in base oil was observed by optical camera. The time dependence dispersity of different concentrated additives was recorded at least eight months by optical images. The VI of different samples were measured with SpectroVisc300 to evaluate their viscosity-temperature behavior.

\subsection{Frictional Performance Test}

The frictional performance test was conducted on four-ball tester (MRS-10B) with a load of $396 \mathrm{~N}$ at $75^{\circ} \mathrm{C}$ for $60 \mathrm{~min}$. The maximum nonseizure load $\left(\mathrm{P}_{\mathrm{B}}\right.$ value), sintering load $\left(\mathrm{P}_{\mathrm{D}}\right.$ value) and the wear scar diameter (WSD) of lubricating oil were measured to study the tribological effect of EOG additive. The frictional performance of refined oil was tested as well to assess the universal lubricating effect of EOG in diverse oil.

\section{Results and Discussion}

\subsection{Structure Characterization}

${ }^{13} \mathrm{C}$-NMR was performed to study the chemical structure of various samples. As shown in Fig. 1a, the peaks appeared at 17 ppm and $30 \mathrm{ppm}$ were the carbons in $-\mathrm{CH}_{3}$ and $-\mathrm{CH}_{2}-$ of oleylamine, respectively. ${ }^{29,30}$ It confirms the existence of oleylamine in the edge functionalized graphene. The peak at $130 \mathrm{ppm}$ attributed to the graphitic $\mathrm{C}$ of the graphene. The carbon appeared at 160 ppm was $\mathrm{C}$ in amide group (-CONH-), which indicated the success condensation between $-\mathrm{NH}_{2}$ of oleylamine and - $\mathrm{COOH}$ of carboxylated graphene. ${ }^{31}$ The chemistry of different samples was further characterized by FTIR (Fig. 1b). The strong peak at $3431 \mathrm{~cm}^{-1}$ attributed to the crystal water associated with $\mathrm{KBr}$. Carbonyl peak in ECG and EOG can be clearly seen at $1720 \mathrm{~cm}^{-1}$ and $1706 \mathrm{~cm}^{-1}$, respectively. ${ }^{32}$ The strong peaks at $2923 \mathrm{~cm}^{-1}$ and $2853 \mathrm{~cm}^{-1}$ in EOG were the methyl and methylene group in oleylamine..$^{21,33}$ The FTIR spectrum of ECG showed a unique sharp peak for $\mathrm{C}-\mathrm{O}$ stretching at $1250 \mathrm{~cm}^{-1}$ exclusively from $\mathrm{O}=\mathrm{C}-\mathrm{OH}$ comparing to EOG. ${ }^{24,34}$ In addition, the FTIR spectrum of EOG showed another unique sharp peak stretching at $1454 \mathrm{~cm}^{-1}$ attributed to -CONH-. ${ }^{35}$ The forming of amide group and disappearing of C-O group in EOG demonstrate that the oleylamine has been successfully grafted to the graphene edge via carboxyl and amine condensation.

The elemental analysis (Table 1) showed that the amount of nitrogen and hydrogen increased and the oxygen decreased in EOG comparing to ECG. The increasing of nitrogen and hydrogen is because of the introducing of oleylamine to ECG. On the other hand, the condensation between carboxyl and amine groups removes water, therefore resulting in the decreasing of oxygen.

Fig. 2a showed the typical Raman spectra of ECG and EOG. Both of them displayed similar D peak around 1355 $\mathrm{cm}^{-1}$ and $\mathrm{G}$ peak around $1599 \mathrm{~cm}^{-1}$. The $\mathrm{I}_{\mathrm{D}} / \mathrm{I}_{\mathrm{G}}$ of ECG was 1.06 , indicating the significant edge distortion due to grain

Table 1 Elemental analysis of ECG and EOG.

\begin{tabular}{ccccc}
\hline Materials & $\mathrm{C}(\%)$ & $\mathrm{H}(\%)$ & $\mathrm{O}(\%)$ & $\mathrm{N}(\%)$ \\
\hline ECG & 70.760 & 1.087 & 27.843 & 0.110 \\
EOG & 84.240 & 6.174 & 7.326 & 2.080 \\
\hline
\end{tabular}
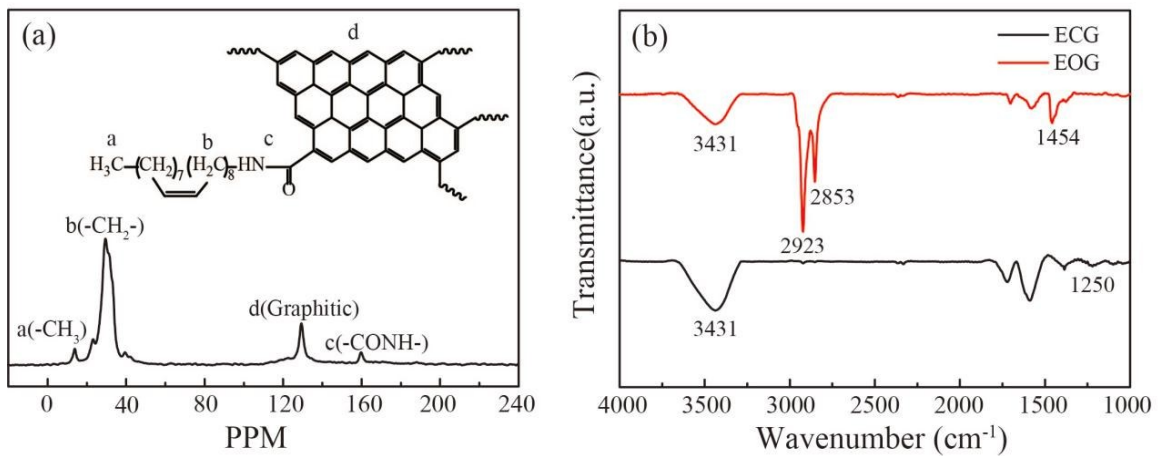

Fig. $1{ }^{13} \mathrm{C}-\mathrm{NMR}$ (a) of EOG and FTIR (b) of ECG and EOG. 

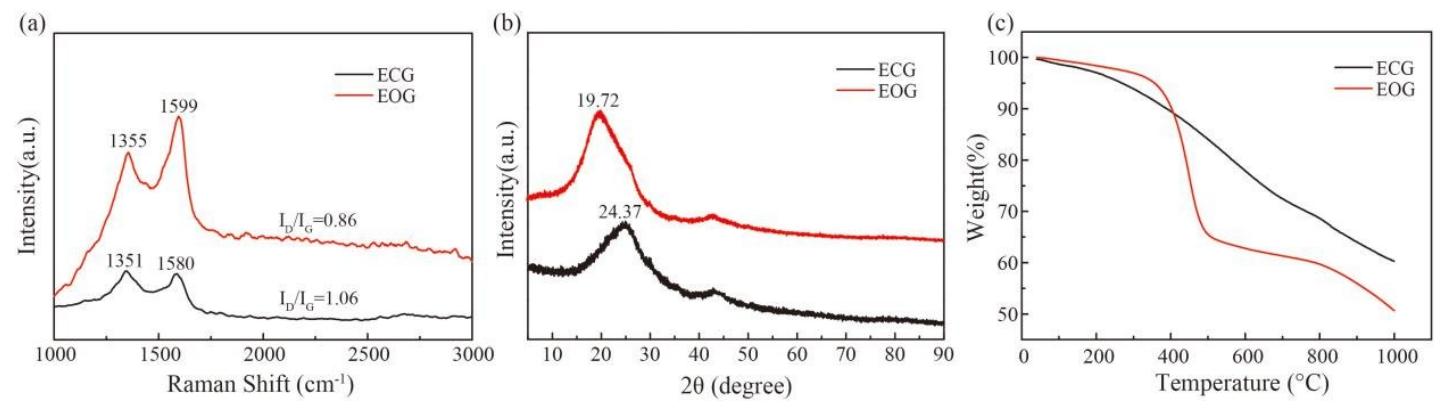

Fig. 2 Raman (a), XRD (b) and TGA (c) spectra of ECG and EOG.

size reduction and carboxylation. ${ }^{24}$ After the oleylamination, EOG showed a lower $I_{D} / I_{G}$ of 0.86 . The oleylamine has been widely used as reducing agent in nanomaterials synthesis. The ECG might be also reduced by oleylamine during the grafting process. Therefore the $I_{D} / I_{G}$ ratio was slightly decreased. Besides, the formed amide group had strong $\mathrm{N}-\mathrm{H}$ deformation at $1626 \mathrm{~cm}^{-1}$ and $\mathrm{C}=\mathrm{O}$ stretching at $1664 \mathrm{~cm}^{-1} .{ }^{36}$ The $\mathrm{C}=\mathrm{C}$ peak of oleylamine also appeared around $1650 \mathrm{~cm}^{-1} .{ }^{37}$ These peaks were overlapped with the $\mathrm{G}$ band of graphene, which might affect $\mathrm{I}_{\mathrm{D}} / \mathrm{I}_{\mathrm{G}}$ ratio as well. The XRD diffraction pattern in Fig. $2 b$ showed a broad peak at $24.37^{\circ}$ for ECG and $19.72^{\circ}$ for EOG. It demonstrated that both of the ECG and EOG were amorphous structures after ball milling. The large shift of EOG comparing to ECG should attribute to the swelling effect of oleylamine. The thermal stability of ECG and EOG was studied by TGA as shown in Fig. 2c. The ECG slowly lost its weight with temperature increasing, while the EOG had a significant weight loss from $400{ }^{\circ} \mathrm{C}$ to $500{ }^{\circ} \mathrm{C}$. It indicates that the ECG was more stable than EOG at higher temperature. The reason is that the oleylamine in EOG started to decompose above $400^{\circ} \mathrm{C}$.

The typical TEM image of EOG particles (Fig. 3a) clearly showed that it had sheet-like microstructure. The thickness of EOG sheet was about $4.80 \mathrm{~nm}$ as measured by AFM in Fig. 3b, which indicated that the EOG was composed of several layered graphene.

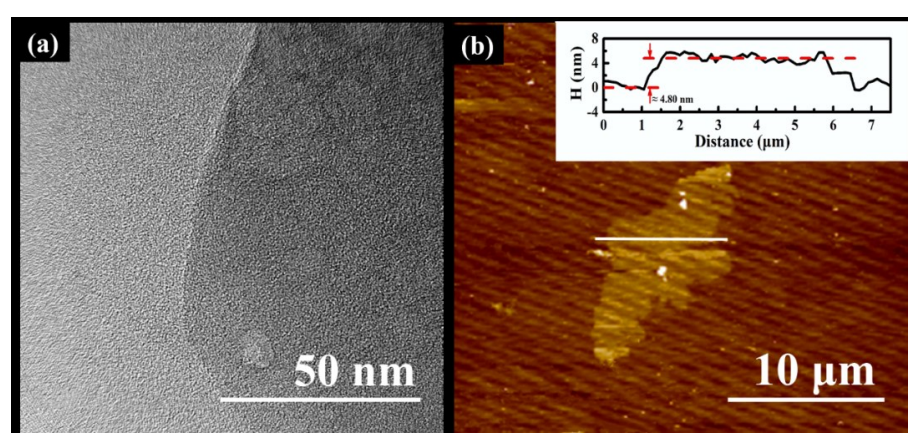

Fig. 3 (a) TEM and (b) AFM images of EOG.

\subsection{Dispersity and Viscosity Index Measurement}

The dispersity and time-dependence stability of graphene additive in base oil were recorded by optical images as shown in Fig. 4. Both ECG and EOG were well dispersed in the base oil at the beginning. It was because that the ballmilling process produced very thin layer graphene, which was more easy to disperse in base oil than thick graphene particles. However, most of the ECG additives aggregated and precipitated at the bottom of glass vial within one week (Fig. 4, sample a). The reason is that the hydrophilic carboxyl functional group tended to aggregate together in the oil phase, which finally lead to the sedimentation of ECG. On the contrary, EOG was well dispersed in base oil and it could be quite stable for at least eight months. Obviously, the oleophilic edge of EOG strongly promoted

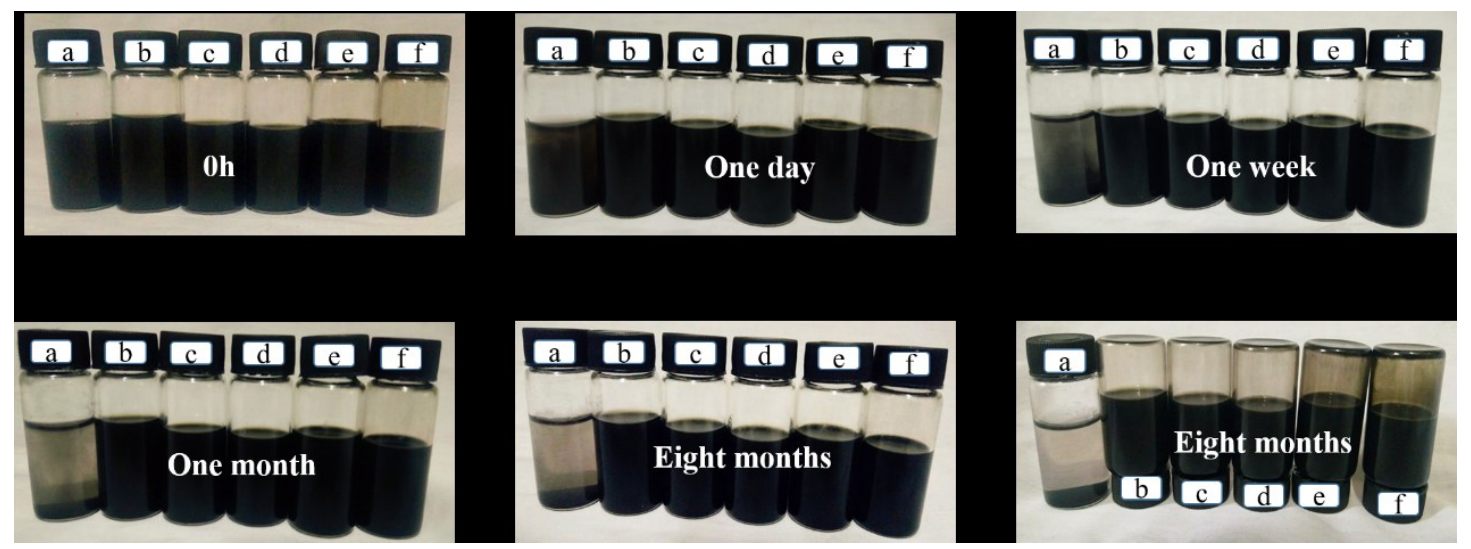

Fig. 4 The time-dependence dispersion of ECG and EOG additive in base oil. 
the affinity between graphene and oil. Besides, the longchain oleylamine reduced the stacking effect that originated from the $\pi-\pi$ interaction between graphene layers. Thus the EOG exhibited long-term stability in the base oil. However, the dispersing amount of EOG in base oil was still limited. When the concentration of EOG was increased over 0.5 wt.\%, sedimentation occurred after long-term standing. It is because large amount of EOG increases their aggregation opportunity in the oil.

Petroleum ether and mineral oil were selected as model oils to evaluate the wettability of EOG for their viscosity difference. As shown in Fig. 5, the contact angle of EOG to petroleum ether and mineral oil are $10.7^{\circ}$ and $41.3^{\circ}$, respectively. It indicates that EOG has an oleophilic property, which is deemed to be beneficial for EOG dispersing in oil. The intrinsic oleophilicity could be the key factor for the well dispersing of EOG in lubricating oil.

(a)

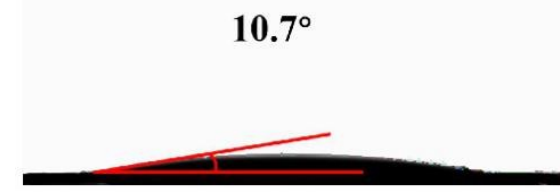

(b)

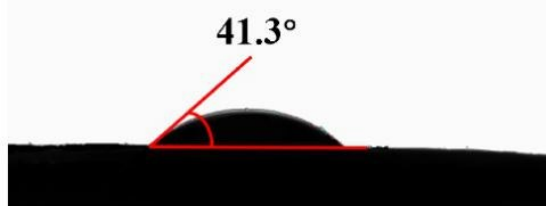

Fig. 5 Contact angle measurements of EOG with petroleum ether (a) and mineral oil (b).

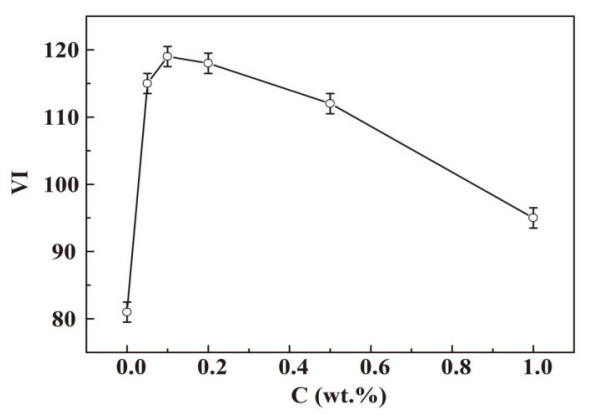

Fig. 6 VI value of lubricant with different EOG amount.

The viscosity-temperature behavior of lubricating oils was evaluated by VI value. Large VI value means small viscosity change of lubricating oil along with temperature, which stands for high quality lubricant. The VI of different samples were calculated and organized in Fig. 6. It is clear that the base oil had the lowest VI of 81. The VI of lubricants were increased after adding EOG additives. Besides, the VI reached the highest value of 119 for the lubricant sample with $0.1 \mathrm{wt} . \%$ EOG. According to the general lubricant classification of Society of Automotive Engineers standard (SAE, SAE standards J 300 and J 306), lubricants with VI in the range 80 110 are classified as high-grade product, and lubricants with VI above 110 are very high-grade products. It demonstrates that EOG upgraded the base oil from high-grade to very highgrade product in this work. The improvement of viscositytemperature behavior of base oil by adding EOG might come from the superior lubricating properties and thermal conductivity of graphene. The adding of EOG changed the initial viscosity of base oil, which reduced the variation of viscosity at different temperature. ${ }^{38,39}$ At the same time, EOG improved the thermal conductivity of lubricants, which led to a homogeneous temperature distribution in lubricants, hence reduced the viscosity change with temperature. ${ }^{36}$ The VI value started to decrease when the EOG concentration over $0.1 \mathrm{wt} . \%$. It is because the viscosity of lubricant increases with the concentration increasing and the high viscosity has become the main factor to drive VI.

\subsection{Friction Performance}

$\mathrm{P}_{\mathrm{B}}, \mathrm{P}_{\mathrm{D}}$ and WSD of different samples were measured at least 3 times to reduce the deviation. As can be seen in Fig. 7, the $\mathrm{P}_{\mathrm{B}}$ and $\mathrm{P}_{\mathrm{D}}$ of base oil were improved while WSD was reduced by adding EOG additive. It indicates that the EOG can effectively improve the friction performance of lubricating oil. The lubricating sample with $0.1 \mathrm{wt} . \%$ EOG exhibited the highest $P_{B}$ and $P_{D}$ value and lowest WSD. The $\mathrm{P}_{B}$ value increased up to $549 \mathrm{~N}$, which is $64.86 \%$ higher than the base oil. At the same time, the $\mathrm{P}_{\mathrm{D}}$ value went up to $1960 \mathrm{~N}$, which was $56.18 \%$ higher than base oil. The 0.1 wt.\% EOG modified lubricant also expressed the best WSD of $0.46 \mathrm{~mm}$ comparing to the original base oil of $0.88 \mathrm{~mm}$ (Fig. 7c). There might be two main reasons for the friction performance enhancement. First, the EOG nano-sheets repair the pitting on friction pair surface and reduce the surface roughness. Second, the absorbed EOG nano-sheets on the surface lead to high lubricating thin film between friction pair surfaces for their intrinsic low sliding resistance properties. Besides the EOG is deemed to be good for the wear resistance due to the high mechanical strength of graphene. However, too much EOG will result in thick grain-like film on the frictional pair surface, which brings down the lubricating effect of EOG.

In order to extend the lubricating applications of EOG, refined oil was used as another base oil to study the frictional performance. As summarized in Table 2, $\mathrm{P}_{\mathrm{B}}$ value and $P_{D}$ value of refined oil were increased and WSD was decreased after adding $0.1 \mathrm{wt} . \%$ EOG. At the same time, the coefficient of friction (COF) decreased from 0.1 to 0.05 . It indicates that the lubricating properties of refined oil is 
Table 2 The friction performance of the original refined oil and EOG modified refined oil.

\begin{tabular}{ccc}
\hline & Refined oil & EOG-refined oil $(0.1 \mathrm{wt} . \%)$ \\
\hline COF & 0.10 & 0.05 \\
WSD & 0.55 & 0.35 \\
$\left(396 \mathrm{~N}, 75^{\circ} \mathrm{C}, 60 \mathrm{~min}\right)$ & 1050 & 1160 \\
$\mathrm{P}_{\mathrm{B}}, \mathrm{N}$ & 1950 & 2730 \\
$\mathrm{P}_{\mathrm{D}}, \mathrm{N}$ & & \\
\hline
\end{tabular}

(a)

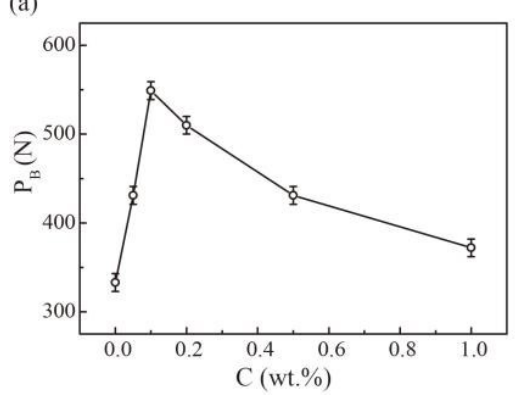

(b)



(c)



Fig. 7 The $P_{B}(a), P_{D}(b)$ and WSD (c) value of samples with different EOG concentration.

strongly improved by adding EOG additive. The similar results of different base oil indicate that the EOG has an universal lubricating effect for diverse oils.

\section{Conclusion}

In this work, we prepared a highly dispersive lubricating additives by oleylaminating the graphene via ball-milling method. The EOG modified lubricant was quite stable under static condition for at least 8 months. The EOG expressed superior dispersibility and stability in lubricating oil and refined oil for the oleophilic chain of oleylamine. The oleophilic EOG was able to disperse in the base oil with relative high concentration of $1 \mathrm{wt} . \%$. The VI value of lubricant, as represented the viscosity-temperature behavior, was strongly improved from 81 to 119 for the high thermal conductivity of EOG. The EOG upgraded the base oil from high grade to very high grade product. Besides, the nanosheeted EOG reduced the roughness of friction pair surfaces and formed thin-lubricating film between them, hence improving the friction performance. In a word, we present a facile way to massively prepare highly dispersive lubricating additives with applicability in diverse oils. The remarkable stability and lubricating properties make EOG promising additive in commercial applications.

\section{Conflict of Interest}

There are no conflicts to declare.

\section{Acknowledgements}

The authors are grateful for the support by the National Key
Research and Development Program of China [2017YFA0206500]; NSF of China [51502012; 21676020; 21620102007]; Beijing Natural Science Foundation [17L20060, 2162032]; Young Elite Scientists Sponsorship Program by CAST [2017QNRC001]; The Start-up fund for talent introduction of Beijing University of Chemical Technology [buctrc201420; buctrc201714];. Talent cultivation of State Key Laboratory of Organic-Inorganic Composites; Distinguished scientist program at BUCT [buctylkxj02] and the "111" project of China [B14004].

\section{References}

1. K. Holmberg, P. Andersson and A. Erdemir, Tribol. Int., 2012, 47, 221234.

2. K. Holmberg, P. Kivikytö-Reponen, P. Härkisaari, K. Valtonen and A. Erdemir, Tribol. Int., 2017, 115, 116-139.

3. C. Altavilla, M. Sarno, P. Ciambelli, A. Senatore and V. Petrone, Nanotechnology, 2013, 24, 125601.

4. L. Chen, J. Han, L. Ge, L. Fan and R. Guo, J. Colloid Interf. Sci., 2018, 522, 200-207.

5. M. Esquivel-Gaon, N. H. A. Nguyen, M. F. Sgroi, D. Pullini, F. Gili, D. Mangherini, A. I. Pruna, P. Rosicka, A. Sevcu and V. Castagnola, Nanoscale, 2018, 10, 6539-6548.

6. S. P. Ingole, Tribol. Sci. Eng., 2013, 269-291.

7. WATANABE, NOSHIRO and MIYAKE, Surf. Coat. Tech., 2004, 183, 347-351.

8. M. R. Hilton, R. Bauer, S. V. Didziulis, M. T. Dugger, J. M. Keem and J. Scholhamer, Surf. Coat. Tech., 1992, 53, 13-23.

9. K. Kwang-Seop, L. Hee-Jung, L. Changgu, L. Seoung-Ki, J. Houk, A. Jong-Hyun, K. Jae-Hyun and L. Hak-Joo, Acs Nano, 2011, 5, 5107-5114.

10. E. Shamsaei, F. B. de Souza, X. Yao, E. Benhelal, A. Akbari and W. Duan, Constr. Build. Mater., 2018, 183, 642-660.

11. M. S. Won, O. V. Penkov and D. E. Kim, Carbon, 2013, 54, 472-481.

12. D. Berman, A. Erdemir and A. V. Sumant, Carbon, 2013, 54, 454-459. 
13. J. Guo, C. Y. Lin, Z. Xia and Z. Xiang, Angew. Chem. Int. Ed. Engl., 2018, 57, 12567-12572.

14. S. Bagheri, N. Jamal, A. Halilu and A. TermehYousefi, Sci. Rep., 2018, 8, 6221 .

15. B. L. Dasari, J. M. Nouri, D. Brabazon and S. Naher, Energy, 2017, 140, 766-778.

16. Y. Zhong, Z. Zhen and H. Zhu, Flat. Chem, 2017, 4, 20-32.

17. X. Fan, Y. Xia, L. Wang and W. Li, Tribol. Lett., 2014, 55, 455-464.

18. K. Hu, D. D. Kulkarni, I. Choi and V. V. Tsukruk, Prog. Poly. Sci., 2014, 39, 1934-1972.

19. J. R. Potts, D. R. Dreyer, C. W. Bielawski and R. S. Ruoff, Polymer, 2011, 52, 5-25.

20. S. Stankovich, R. D. Piner, S. B. T. Nguyen and R. S. Ruoff, Carbon, 2006, 44, 3342-3347.

21. J. Lin, L. Wang and G. Chen, Tribol. Lett., 2010, 41, 209-215.

22. S. Bagheri, N. Jamal, A. Halilu and A. Termehyousefi, Sci. Rep., 2018, 8, 6221 .

23. I. Y. Jeon, H. J. Choi, S. M. Jung, J. M. Seo, M. J. Kim, L. Dai and J. B. Baek, J. Am. Chem. Soc., 2013, 135, 1386-1393.

24. I. Y. Jeon, Y. R. Shin, G. J. Sohn, H. J. Choi, S. Y. Bae, J. Mahmood, S. M. Jung, J. M. Seo, M. J. Kim, D. Wook Chang, L. Dai and J. B. Baek, Proc. Natl. Acad. Sci. USA., 2012, 109, 5588-5593.

25. Z. Xiang, Q. Dai, J. F. Chen and L. Dai, Adv. Mater, 2016, 28, 62536261.

26. Y. Zhao, M. Niu, F. Yang, Y. Jia and Y. Cheng, Eng. Sci., 2019.

27. M. Borah, M. Dahiya, S. Sharma, R. B. Mathur and S. R. Dhakate,
Mater. Focus, 2014, 3, 300-309.

28. L. J. Treadwell, T. J. Boyle, N. S. Bell, M. A. Rodriguez, B. R. Muntifering and K. Hattar, J. Mater. Sci., 2017, 52, 8268-8279.

29. H. Pereira, P. C. Lemos, M. A. M. Reis, J. P. S. G. Crespo, M. J. T. Carrondo and H. Santos, Water Res., 1996, 30, 2128-2138.

30. B. A. Johnson and R. A. Blevins, J. Biomol. Nmr., 1994, 4, 603-614.

31. J. Tuominen and J. V. Seppälä, Macromolecules, 2000, 33, 3530-3535.

32. S. Gahlot, V. Kulshrestha, G. Agarwal and P. K. Jha, Macromol. Symp., 2016, 357, 173-177.

33. Z. Liao, Y. Wang, Q. Wang, Y. Cheng and Z. Xiang, Appl. Catal. B: Environ., 2019, 243, 204-211.

34. S. Korkmaz, F. Meydaneri Tezel and İ. A. Kariper, J. Alloy. Compd., 2018, 754, 14-25.

35. C. Xiao and H. E. Yueying, Polymer, 2006, 47, 474-479.

36. P. G. Puranik and K. V. Ramiah, Proc. Indian Acad. Sci A, 1961,54, 6979

37. D. Baranov, M. J. Lynch, A. C. Curtis, A. R. Carollo, C. R. Douglass, A. M. Mateo-Tejada and D. M. Jonas, Chem. Mater. 2019, 31, 1223-1230

38. M. Osama, R. Walvekar, M. Khalid, A. K. Rasheed, W. Y. Wong and T. C. S. M. Gupta, J. Clean. Prod., 2018, 193, 277-289.

39. D. Wei and J. Kivioja, Nanoscale, 2013, 5, 10108-10126.

Publisher's Note Engineered Science Publisher remains neutral with regard to jurisdictional claims in published maps and institutional affiliations. 